\section{A Model for Estimating Area of Muskmelon Leaves}

\author{
G.R. Panta ${ }^{1}$ and D.S. NeSmith ${ }^{2}$ \\ Department of Horticulture, Georgia Experiment Station, Griffin, \\ GA 30223-1797
}

Additional index words. growth analysis, leaf growth, leaf expansion

\begin{abstract}
Eight muskmelon (Cucumis melo reticulatus L.) cultivars were selected to test whether a model could be developed to estimate leaf area across cultivars. Regression analyses of leaf area vs. leaf width and length revealed several models that could be used for estimating the area of individual muskmelon leaves. A linear model using leaf width squared was the best overall, yielding the equation $A=3.3+0.63\left(W^{2}\right)$, where $A$ is area of an individual leaf lamina (square centimeter) and $W$ is leaf width (centimeter) at the widest point perpendicular to the leaf midrib. Forcing the intercept through the origin did not significantly alter prediction capability and resulted in a simple model of the form $A=0.64$ $\left(\mathbf{W}^{2}\right)$ that was applicable to all eight cultivars.
\end{abstract}

Measurement of leaf area is often necessary for agronomic and physiological studies, and many methods of estimating leaf area have been developed (Wiersma and Bailey, 1975). Generally, estimation procedures involve measurement of leaf length or width and the correlation of these characteristics, via regression, with actual leaf area. Accurate, nondestructive methods of estimating leaf area are useful in studying the relationship between leaf area development and plant growth (Robbins and Pharr, 1987). These methods permit repeated sampling of the same plants over time, thus facilitating the study of leaf dynamics not possible with destructive sampling procedures (NeSmith, 1992).

Simple, accurate leaf area prediction models can be substituted for expensive leaf area meters and time-consuming geometric reconstructions (Gamiely et al., 1991). There are occasions when collected leaf samples are soiled, and in such cases, determination of leaf area with an area meter may result in a high degree of error. An estimation of leaf area from leaf length or width is not affected by such problems. Additionally, nondestructive methods of leaf area assessment may be the best alternative where available equipment is limited due to financial constraints, and where low labor costs can offset those of expensive machinery. The objective of this investigation was to test whether a leaf area estimation model could be derived for several muskmelon cultivars from linear measurements of leaf length and width.

Received for publication 25 Aug. 1994. Accepted for publication 18 Dec. 1994. A contribution of the Univ. of Georgia Agricultural Experiment Station, Georgia Station, Griffin. This research was supported by state and Hatch Act funds allocated to the Georgia Agricultural Experiment Stations. The cost of publishing this paper was defrayed in part by the payment of page charges. Under postal regulations, this paper therefore must be hereby marked advertisement solely to indicate this fact.

${ }^{1}$ Graduate Research Assistant.

${ }^{2}$ Assistant Professor. domly collected for each cultivar after flowering ( $\approx 60$ days after sowing). Leaf length (L) was measured from the lamina tip to the petiole attachment point (Robbins and Pharr, 1987). Leaf width (W) was considered as the widest point perpendicular to the lamina midrib (NeSmith, 1992). The range in L of selected leaves was 1 to $18 \mathrm{~cm}$ and the range in $\mathrm{W}$ was 1 to $25 \mathrm{~cm}$. Actual individual leaf area (A) was determined with a commercial leaf area meter (model 3100; LI-COR, Lincoln, Neb.). The data were analyzed using regression procedures. The dependent variable $\mathrm{A}$ was regressed with different independent variables, including $\mathrm{L}, \mathrm{W}, \mathrm{L}^{2}, \mathrm{~W}^{2}$, and the product of $\mathrm{L} \times \mathrm{W}$. These statistics were applied to each individual cultivar and to combined data points of all cultivars for each model.

After determining the best leaf area estimation model, a validation was conducted in Summer 1994 on leaf samples obtained from muskmelons grown at two locations in Georgia. Seeds and 3-week-old transplants of the plants to be used in the validation were planted in Plains, Ga., in early April, and in Griffin, Ga., in early May. About 25 leaf samples were obtained from transplanted and direct-seeded crops 40 to 50 days after sowing for 'Magnum .45 ', 'Cordele', and 'Primo'. Actual leaf area and leaf width were determined by the previously described procedures. Leaf area of individual leaves was predicted using the best model and was compared with the actual leaf area.
Table 1. Models, coefficients of determination $\left(r^{2}\right)$, and mean square error (MSE) of correlations between muskmelon leaf area (A) and leaf length (L) and width (W) (combined data for eight muskmelon cultivars). Units for $\mathrm{A}$ are square centimeters and for $\mathrm{L}$ and $\mathrm{W}$ are centimeters.

\begin{tabular}{lcr}
\hline \hline Models & $r^{2}$ & MSE \\
\hline $\mathrm{A}=3.30+0.63\left(\mathrm{~W}^{2}\right)$ & 0.98 & 162 \\
$\mathrm{~A}=-4.36+1.14\left(\mathrm{~L}^{2}\right)$ & 0.94 & 421 \\
$\mathrm{~A}=-2.47+0.86(\mathrm{~L} \times \mathrm{W})$ & 0.98 & 173 \\
$\mathrm{~A}=-5.95+0.42(\mathrm{~L})+1.12\left(\mathrm{~L}^{2}\right)$ & 0.94 & 421 \\
$\mathrm{~A}=-5.76+1.85(\mathrm{~W})+0.55\left(\mathrm{~W}^{2}\right)$ & 0.98 & 157 \\
\hline
\end{tabular}

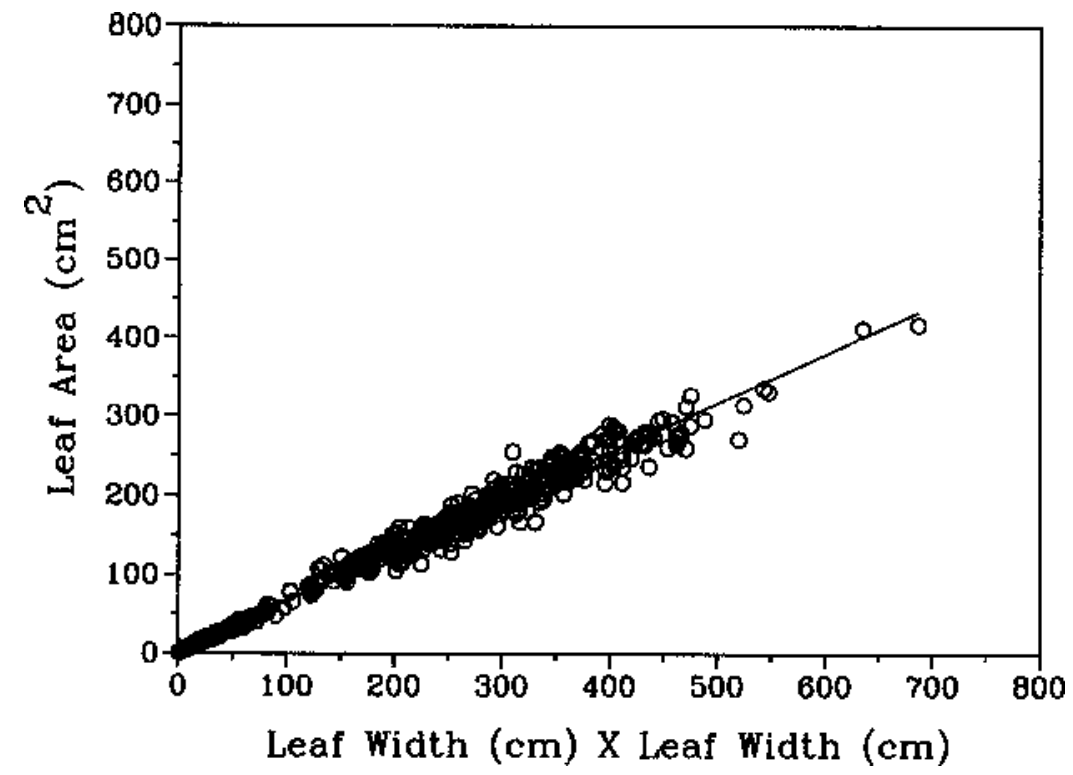

Fig. 1. Leaf area (A) of eight muskmelon cultivars as a function of leaf width (W). The equation for the regression line is $\mathrm{A}=3.30+0.63\left(\mathrm{~W}^{2}\right)$. 
Table 2. Intercepts, slopes, coefficients of determination $\left(r^{2}\right)$, and mean square error (MSE) for individual cultivars using the model $\mathrm{A}=\mathrm{a}+\mathrm{b}\left(\mathrm{W}^{2}\right)$, where $\mathrm{A}$ is leaf area (square centimeter), $\mathrm{a}$ is the intercept, $\mathrm{b}$ is the slope, and $\mathrm{W}$ is leaf width (centimeter).

\begin{tabular}{lcccc}
\hline \hline Cultivar & $\mathrm{a}$ & $\mathrm{b}$ & $r^{2}$ & $\mathrm{MSE}$ \\
\hline Athena & $3.72(3.19)^{\mathrm{z}}$ & $0.59(0.01)$ & 0.98 & 158 \\
Cordele & $4.53(2.61)$ & $0.59(0.01)$ & 0.98 & 117 \\
Goldmark & $1.79(3.00)$ & $0.67(0.01)$ & 0.98 & 147 \\
Magnum .45 & $-1.19(3.09)$ & $0.66(0.01)$ & 0.98 & 148 \\
Supersun & $2.87(2.48)$ & $0.64(0.01)$ & 0.99 & 118 \\
Primo & $1.30(2.14)$ & $0.63(0.01)$ & 0.99 & 92 \\
Tasty Sweet & $3.26(2.33)$ & $0.64(0.01)$ & 0.99 & 90 \\
Zenith & $3.71(2.34)$ & $0.62(0.01)$ & 0.99 & 96 \\
\hline
\end{tabular}

${ }^{\mathrm{z}}$ Values in parentheses are the standard errors of the parameter estimates.

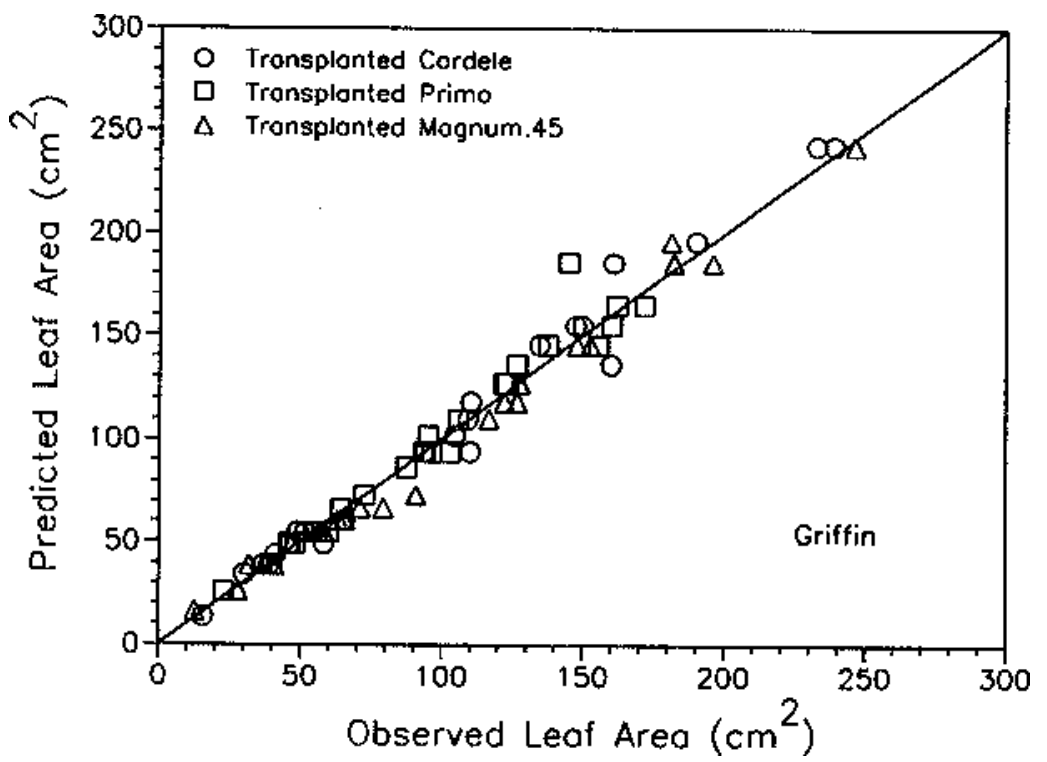

Fig. 2. Observed vs. predicted leaf area for three transplanted muskmelon cultivars at Griffin, Ga., during 1994. The predicted values of leaf area were obtained using the equation from Fig. 1 . The line represents the $1: 1$ relationship between observed and predicted values.

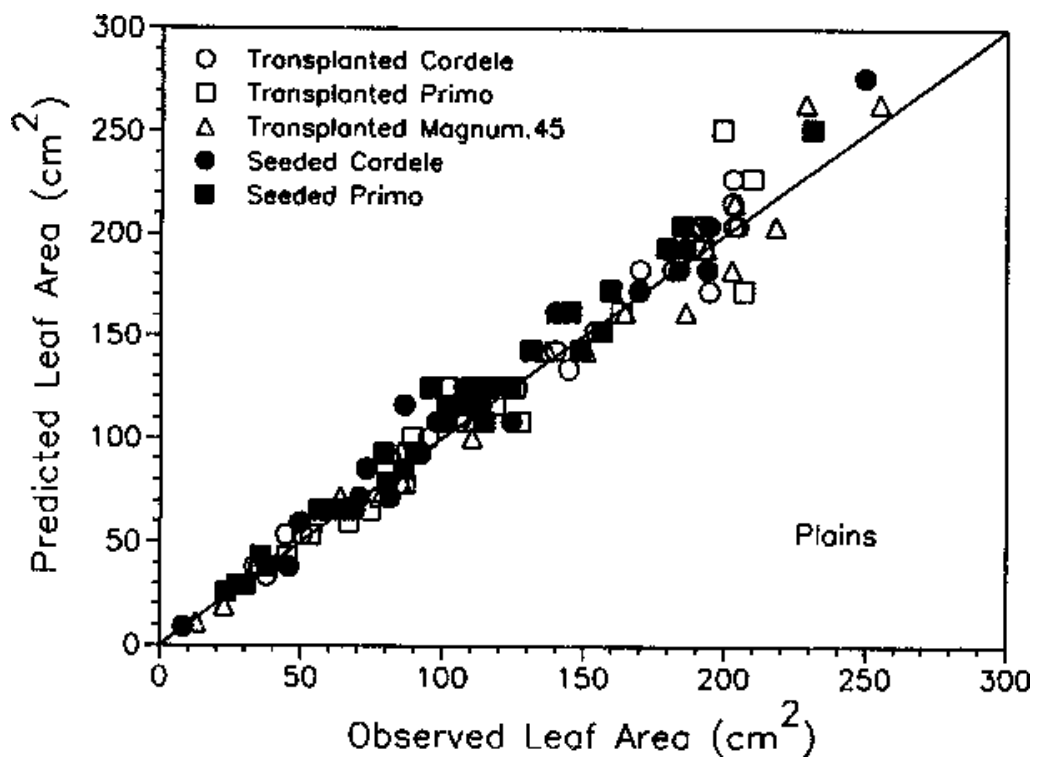

Fig. 3. Observed vs. predicted leaf area for three transplanted and two direct-seeded muskmelon cultivars at Plains, Ga., during 1994. The predicted values of leaf area were obtained using the equation from Fig. 1. The line represents the 1:1 relationship between observed and predicted values.

\section{Results and Discussion}

When leaf area (A) was regressed with leaf width (W) or leaf length (L) alone, a curvilinear relationship was obtained (Table 1). A linear relationship was found between $\mathrm{A}$ and the $\mathrm{W}^{2}, \mathrm{~L}^{2}$, and $\mathrm{L} \times \mathrm{W}$. A second-order polynomial equation also was derived for the parameters $\mathrm{W}$ and $\mathrm{L}$. The linear model having $\mathrm{W}^{2}$ for all cultivars as an independent variable had one of the smallest mean square error (MSE) values and one of the highest $r^{2}$ values (Table 1, Fig. 1). We preferred this linear model because of its simplicity and convenience, as it only involves one variable. Models of similar precision either were more complex or involved additional variables. As stated by Robbins and Pharr (1987), model selection requires a balance between predictive qualities of the model and the economy of including the least number of variables necessary to predict the leaf area.

Possible cultivar differences using the selected model were analyzed. Slopes of the cultivars were slightly different, whereas the intercepts were not (Table 2). However, when leaf area estimations using an equation derived for a single cultivar vs. the overall model were compared, they were not significantly different. This result suggests that a "universal" leaf area estimation model for muskmelon is plausible, unless other cultivars differ greatly in leaf morphology from those used in this experiment.

Comparisons of observed vs. predicted leaf area for Griffin (Fig. 2) and Plains (Fig. 3) validation sites indicated the model worked reasonably well at the two locations. The model would likely be useful under a wide range of environmental conditions, as our experience has shown environment has little influence on leaf geometry (i.e., the overall general shape of leaves).

To have the simplest model, regression was conducted with the intercept forced through the origin. The resulting equation had the same $r^{2}$ value (0.98) and a similar slope (0.64). Leaf area estimations obtained by this model and the previously discussed model were not significantly different (data not shown). Therefore, as a rapid field method, the model $\mathrm{A}=0.64\left(\mathrm{~W}^{2}\right)$ can be used for estimating area of individual muskmelon leaves.

\section{Literature Cited}

Gamiely, S., W.M. Randle, H.A. Mills, and D.A. Smittle. 1991. A rapid and nondestructive method for estimating leaf area of onions. HortScience 26:206.

NeSmith, D.S. 1992. Estimating summer squash leaf area nondestructively. HortScience 27:77.

Robbins, N.S. and D.M. Pharr. 1987. Leaf area prediction for cucumber from linear measurements. HortScience 22:1264-1266.

Wiersma, J.V. and T.B. Bailey. 1975. Estimation of leaf, trifoliate, and total leaf areas of soybeans. Agron. J. 67:26-30. 